\title{
A PROTEÇÃO À LIBERDADE DE EXPRESSÃO NA CORTE INTERAMERICANA DE DIREITOS HUMANOS: UMA ANÁLISE A PARTIR DO ESTADO CHILENO
}

\section{THE PROTECTION OF FREEDOM OF EXPRESSION IN THE INTER-AMERICAN COURT OF HUMAN RIGHTS: AN ANALYSIS OF THE STATE OF CHILE}

\author{
1'Flávia de Ávila \\ ${ }^{2}$ Jose Lucas Santos Carvalho
}

\section{RESUMO}

Esta pesquisa objetiva compreender o tratamento dado à liberdade de expressão pelo Direito Internacional dos Direitos Humanos, especialmente no âmbito regional americano, e a atuação da Corte Interamericana de Direitos Humanos na proteção deste direito, a partir do estudo de casos julgados em face do Chile. Para tanto, utiliza-se de pesquisa teórico-jurídica com tipo metodológico jurídico-exploratório-, análise de conteúdo de textos doutrinários e acadêmicos, normas e dados jurisprudenciais, bem como estudos de caso envolvendo o Estado chileno. Assim, busca-se analisar como as decisões da Corte Interamericana influenciam a evolução do direito humano à liberdade de expressão nos Estados americanos.

Palavras-chave: Liberdade de expressão, Corte interamericana de direitos humanos, Efetividade dos direitos humanos no chile

\begin{abstract}
This research aims to understand the treatment given to freedom of expression under international human rights law, especially in the American regional level, and the work of the Inter-American Court of Human Rights in the protection of this issue by studying cases against Chile. Therefore, it uses theoretical-jurisdictional method -with juridical-exploratory methodological type- analysis of content of doctrinal and academic texts, norms and jurisprudential data and case studies involving the Chilean state. Thus, it seeks to analyze how the Court decisions influence the evolution of the human right to freedom of expression in the American States.
\end{abstract}

Keywords: Freedom of expression, Inter-american court of human rights, Effectiveness of human rights in chile

\footnotetext{
${ }^{1}$ Doutor em Direito pela Pontifícia Universidade Católica de Minas Gerais - PUC, Minas Gerais, Brasil. Professora pela Universidade Federal de Sergipe - UFS, Sergipe (Brasil). E-mail: flaviadeavila@gmail.com

${ }^{2}$ Mestrando em Direito pela Universidade Federal de Sergipe - UFS, Sergipe (Brasil).

E-mail: lucascarvalhodir@hotmail.com
} 


\section{INTRODUÇÃO}

A liberdade e a igualdade são valores que fundamentam o Estado Democrático de Direito, sendo, logo, reconhecidos como instrumentos de promoção e de manutenção das democracias. Nessa concepção, o Estado Democrático de Direito é paradoxal, pois sua atuação permite à pluralidade realizar-se e, ao mesmo tempo, o Estado atua no sentido de controlar o exercício de direitos a um ponto que suas decisões, seletivas em relação à comunidade, afetem o exercício da liberdade. Torres (2012, p. 40-41) sublinha o "[...] sem número de visões de mundo [...]" as quais marcam e compõem as sociedades atuais e levam a democracia aos desafios mais importantes, pois este aspecto aparentemente antagônico do Estado Democrático se constitui em pressuposto de sua existência.

Nessa perspectiva, a liberdade de expressão é uma consequência direta da pluralidade classificada por Hannah Arendt (2007) como própria da condição humana, que realiza no espaço público os interlaces entre política e direito. A ação política humana, considerada livre em sua essência, encontra sua condição de possibilidade coletiva na articulação recíproca com o direito, característica de uma sociedade democrática (TORRES, 2012, p. 42).

O paradoxo da democracia é demonstrado, contudo, quando a limitação da liberdade exercida por intermédio de uma autoridade estatal entra em rota de colisão com a especial capacidade de o ser humano se expressar. Enquanto, para Arendt (2007), a própria liberdade é condição humana; a proteção da liberdade de expressão deriva da contingência, dos parâmetros de convivência humana, os quais são estabelecidos no espaço público. $\mathrm{Na}$ convivência social, o ser humano se utiliza da comunicação como instrumento de expressão de ideias, de sentimentos e de ideologias. O direito à liberdade de expressão é entendido como meio de autorrealização humana ao contribuir para o ser humano agir conforme própria convicção e vontade. Ao regulamentar tais direitos no âmbito internacional, por intermédio de vários instrumentos que contemplam a liberdade de expressão como direito humano, o Estado, ente coletivo e sujeito de direito internacional, atuaria de modo a permitir que a liberdade de expressão se efetivasse como parâmetro de dignidade humana, vértice do sistema internacional dos direitos humanos. A narrativa destes direitos pode ser, então, concebida como forma de reconciliação da humanidade com as condições essenciais de ser humano.

É importante salientar ser o entendimento (que costuma emergir dos documentos internacionais de direitos humanos ao qual estão ligados os estados democráticos, especialmente americanos) de que a consolidação e o desenvolvimento de um Estado democrático e plural dependem da existência deste direito, pois ele é construtor de efetivo 
processo democrático ${ }^{1}$. É, assim, mais um tema limítrofe no Direito Internacional dos Direitos Humanos, pois a análise do exercício do direito humano à liberdade de expressão envolve o exame de outros direitos, igualmente relevantes, e, como reflexo da sociedade multicultural em que vivemos, apresenta diferentes interpretações, por vezes estanques e excludentes.

Além disso, apesar de os Estados aderirem às normas de direitos humanos, firmando compromissos formais na ordem internacional, o cotidiano dessas democracias revela ação estatal tendente a violar esses direitos. Consequentemente, provocam a atuação dos sistemas de proteção, seja em âmbito universal, seja regional. No caso dos Estados americanos, por serem membros da Organização dos Estados Americanos (OEA), as violações são competência da Comissão Interamericana de Direitos Humanos (CIDH) que, entendendo ser o caso e havendo reconhecimento da jurisdição do Estado envolvido, pode provocar a Corte Interamericana de Direitos Humanos (Corte IDH). Esses órgãos passam, então, a assumir relevante papel na concretização dos direitos humanos e a enfrentar grandes desafios em relação à efetividade de suas decisões.

A pesquisa tem como objetivo geral estudar o tratamento dado à liberdade de expressão pelos principais documentos do Direito Internacional dos Direitos Humanos, especialmente no âmbito americano, e a compreensão sobre como a Corte Interamericana de Direitos Humanos pode contribuir para a evolução do direito humano à liberdade de expressão, tendo como delimitação temática o estudo dos julgamentos no Estado chileno. Para que o objetivo geral se alcance, o trabalho desenvolver-se-á de acordo com objetivos específicos, que revelam os passos necessários para se atingir o objetivo geral. Portanto, apresentar os arcabouços teóricos da liberdade de expressão como direito humano, estudar a proteção dos direitos humanos frente à Constituição chilena, analisar os casos emblemáticos contra o Chile processados ante a Corte Interamericana de Direitos Humanos, bem como as mudanças promovidas no direito doméstico chileno em resposta aos mandamentos da Corte IDH, tudo são objetivos específicos deste trabalho.

A escolha deste Estado ocorreu devido ao fato de o Chile ser o Estado americano que mais sofreu condenações na Corte IDH nesta temática. A Corte julgou três emblemáticos casos (Olmedo Bustos e outros vs. Chile; Palamara Iribarne vs. Chile e Claude Reyes e outros vs. Chile), que repercutiram no direito doméstico e que ocasionaram mudanças constitucionais

\footnotetext{
${ }^{1}$ A Declaração de Princípios sobre Liberdade de Expressão, aprovada pela Comissão Interamericana de Direitos Humanos em seu $108^{\circ}$ período ordinário de sessões, celebrado de 16 a 27 de outubro de 2000 , traz em seu preâmbulo que a sua edição decorre da consciência de que "a consolidação e o desenvolvimento da democracia dependem da existência de liberdade de expressão" e da persuasão de que "o direito à liberdade de expressão é essencial para o avanço do conhecimento e do entendimento entre os povos, que conduzirá a uma verdadeira compreensão e cooperação entre as nações do Hemisfério". (CIDH, 2000, online $)$
} 
e vigorosas discussões sobre a concretização do direito humano à liberdade de expressão. Sendo assim, o seguinte problema, refletido nos objetivos geral e específico, apresenta-se na pesquisa: "Como e até que ponto a Corte IDH contribui, no exercício da sua jurisdição, para a efetividade e para o desenvolvimento da liberdade de expressão nos Estados Americanos, especialmente no Chile?".

Para que o questionamento possa ser respondido, foi utilizada, no âmbito da vertente teórico-metodológica das ciências sociais aplicadas, a linha jurídico-teórica, por se aproximar da filosofia do direito ao estudar conceitos, interpretação e aplicação de normas do Direito Internacional dos Direitos Humanos. Consequentemente, adotamos o tipo metodológico jurídico-exploratório, pois analisamos diversos aspectos do direito humano à liberdade de expressão e da atuação da Corte IDH sobre a temática. Valemo-nos, ainda, da técnica de análise de conteúdo de textos doutrinários, acadêmicos e normas, além do levantamento de dados jurisprudenciais da Corte IDH.

\section{CONSIDERAÇÕES SOBRE O DIREITO HUMANO À LIBERDADE DE EXPRESSÃO}

Os direitos de liberdade compreendem antigas reivindicações populares e constituemse em relevantes direitos de uma democracia. Ao lado da igualdade, a liberdade liga-se ao homem e ao conceito de dignidade humana, pedra angular dos Estados Democráticos. Assim, o Estado Democrático de Direito se justifica como meio para guarnecer e estimular essas liberdades (MENDES, 2013), sendo a liberdade de expressão (freedom of speech and expression) considerada uma das quatro liberdades fundamentais que todos os povos do mundo deveriam gozar ${ }^{2}$.

A liberdade de expressão compreende o direito de informação e "para que seja completo no seu objeto normativo, há de contemplar três variáveis: o de informar, o direito de se informar e o direito de ser informado" (CANOTILHO, 2003, p. 43). A primeira dimensão abrange o direito de difundir informações. A segunda, o direito de ser informado sobre os reais acontecimentos e ao conhecimento da sociedade local e global, isto é, o direito de acesso

\footnotetext{
2 Ávila (2014, p. 240-241) explica que, no âmbito das providências tomadas em relação aos Direitos Humanos nos anos que antecederam a existência da Organização das Nações Unidas (ONU), o presidente dos Estados Unidos Franklin Delano Roosevelt dirigiu mensagem ao Congresso Norte-Americano, em 6 de janeiro de 1941, conhecida como Discurso das quatro liberdades, sendo elas: liberdade de expressão (freedom of speech and expression); liberdade de religião (freedom of worship); liberdade face à penúria (freedom from want); e liberdade face ao medo (freedom from fear). As Quatro liberdades influenciaram, nos anos posteriores, a atuação da própria ONU.
} 
à informação, às ideias e às expressões de toda natureza. Na terceira dimensão, está o direito de receber informações. Em todas as dimensões se encontra presente o caráter de pretensão a que o Estado não exerça censura, como mecanismo de fortalecimento da democracia pluralista, diante do exercício lícito desse direito. No entanto, os limites e a tolerância do seu exercício são um dos debates mais polêmicos nas democracias contemporâneas. É nesse sentido que os instrumentos de proteção aos direitos humanos pró́bem manifestações discriminatórias e de ódio, partindo da concepção de que, em um Estado democrático e plural, o abuso do exercício desse direito com o fim de atingir minorias estigmatizadas deve ser repreendido.

Podemos, ainda, tratar o direito à liberdade de expressão por dois vieses diferentes: o individualista e o coletivo. Na sua dimensão individualista, o sujeito de direito, enquanto ser singular, externa licitamente as suas opiniões. Na sua dimensão de conteúdo mais coletivo, em relação a grupos e aos instrumentos de trabalho, a liberdade de expressão refere-se ao direito à liberdade de comunicação social. Deflagramos, portanto, que se trata de um relevante direito e uma das mais antigas reivindicações do ser humano ao longo do tempo.

Torres (2012, p. 45), ao reportar-se ao trabalho de Arendt, fundamenta que restrições à liberdade de expressão não podem ser estabelecidas em abstrato, ou a priori, o que se configuraria como a imposição de uma verdade ou como uma forma de autoritarismo. Desse modo, a exposição pública de opiniões não poderia ter qualquer obstáculo ou censura. Para Arendt (2007), somente somos capazes de conhecer a nós mesmos a partir da saída da esfera privada e da exposição no espaço público, em que as relações interpessoais são intensificadas. Tornamo-nos, portanto, concomitantemente, vulneráveis diante das imprevisibilidades e ativos no debate, isto é, prontos para o início de algo novo.

Apesar de a liberdade de expressão ser uma construção bem antiga, sua defesa como direito humano não é remota. Sua origem está no período iluminista, tendo, notadamente, como ponto de partida, a Declaração Francesa dos Direitos do Homem e do Cidadão de 1789. Sua consolidação em âmbito internacional e na perspectiva ocidental deu-se com a Declaração Universal dos Direitos Humanos, de 10 de dezembro de $1948^{3}$ (SISSE, 2015).

A Declaração Universal dos Direitos Humanos (DUDH) ${ }^{4}$ preconiza em seu art. 19 que “Toda pessoa tem direito à liberdade de opinião e expressão; este direito inclui a liberdade de,

\footnotetext{
${ }^{3}$ Resolução da Assembleia Geral da ONU 217 A (III), 10 de dezembro de 1948.

${ }^{4} \mathrm{O}$ direito de acesso à informação constitui uma importante vertente sobre o tema e foi aprimorado ao longo da evolução do DIDH, pois: [a] informação é um fundamento essencial da democracia em todos os níveis. Em sentido mais genérico, a democracia gira em torno da capacidade dos indivíduos de participar de modo efetivo
} 
sem interferência, ter opiniões e de procurar, receber e transmitir informações e ideias por quaisquer meios e independentemente de fronteiras" (NAÇÕES UNIDAS, 1948). No entanto, a DUDH surge, na ordem internacional, desprovida de força normativa, o que, inicialmente, fragiliza a exigência de seu cumprimento, por não gerar sanções àqueles transgressores das suas disposições. No entanto, a sua aplicação nos anos seguintes contribuiu para considerá-la fonte do Direito Costumeiro.

Ainda no nível do sistema universal, o Pacto Internacional sobre os Direitos Civis e Políticos (PIDCP), de 16 de dezembro de $1966^{5}$, dispõe em seu art. 19 que "1. ninguém poderá ser molestado por suas opiniões.”, além disso, “2. Toda pessoa terá direito à liberdade de expressão; esse direito incluirá a liberdade de procurar, receber e difundir informações e ideias de qualquer natureza, independentemente de considerações de fronteiras, verbalmente ou por escrito, em forma impressa ou artística, ou por qualquer outro meio de sua escolha." (NAÇÕES UNIDAS, 1966).

Analisando o conteúdo do Pacto, constatamos que a liberdade de expressão tutela a palavra oral e escrita, a linguagem de signos, além de expressões não verbais, isto é, qualquer manifestação do pensamento humano. Já os meios de comunicação compreendem livros, periódicos, folhetos, bem como as formas de expressões audiovisuais, eletrônicos e de internet. Tal abrangência foi confirmada pelo Comitê dos Direitos Humanos (CDH), na sua Observação Geral nº 34 de 2011, ao interpretar o parágrafo $2^{\circ}$ do artigo 19 do referido PIDCP. Estatui, ainda, que a liberdade de expressão e de opinião são condições indispensáveis para o pleno desenvolvimento da pessoa. São fundamentais para toda sociedade e constituem "la piedra angular de todas las sociedades libres y democráticas" (COMITÉ DE DERECHOS HUMANOS, 2011, online).

Entretanto, o seu limite também encontra definido no texto, pois a não definição de seus contornos vulneraria outros direitos humanos que podem ser atingidos no abuso do exercício desse direito. Nesse ponto, o parágrafo $3^{\circ}$ dispõe que o exercício do direito previsto no parágrafo $2^{\circ}$ implicará deveres e responsabilidades especiais, com a submissão de restrições que devem ser expressamente previstas em lei e necessárias para: “a) assegurar o respeito dos direitos e da reputação das demais pessoas; b) proteger a segurança nacional, a ordem, a saúde ou a moral públicas.”. Pró́be-se, com isso, a violação aos direitos do outro e as condutas contra a segurança. Outro dispositivo do Pacto proíbe a apologia do ódio (artigo

da tomada de decisões que os afeta (MENDEL, 2009, p. 4). É através deste direito que o cidadão tem acesso ao conteúdo das decisões políticas, participando ativamente da vida democrática.

${ }^{5}$ Resolução da Assembleia Geral da ONU 2200 A (XXI), de 16 de dezembro de 1966, com entrada em vigor em 23 de março de 1976. 
20). Ademais, a Comissão da ONU para os direitos humanos, em 1993, estabeleceu o escritório do Relator Especial da ONU para a Liberdade de Opinião e Expressão. Mendel (2009) explica que o Relator Especial da ONU junto a outros detentores de cargos dedicados ao tema, estabelecidos por outras organizações internacionais, emitem, desde 1999, Declaração Conjunta anual acerca dos diferentes temas afeitos à liberdade de expressão. Desse modo, o direito humano à liberdade de expressão adquiriu ao longo dos anos uma maior concentração de esforços para o refinamento de conceitos e a implementação desse direito.

No sistema regional de direitos humanos, no âmbito americano, a Convenção Americana sobre Direitos Humanos (Pacto de San José da Costa Rica), de 22 de novembro de 1969, é o marco legal a que estão sujeitos os Estados membros da OEA ${ }^{6}$. O art. 13 da Convenção trata da liberdade de pensamento e de expressão assegurando que esse direito “compreende a liberdade de buscar, receber e difundir informações e ideias de toda natureza, sem consideração de fronteiras, verbalmente ou por escrito, ou em forma impressa ou artística, ou por qualquer outro processo de escolha". Outrossim, a norma também se preocupou em vedar a restrição ao direito à liberdade de expressão pela via ou meios indiretos, isto é, o uso de controles oficiais ou particulares destinados a obstar a comunicação e a circulação de ideias ou opiniões.

O Pacto de San José vedou a censura prévia. No entanto, é possível haver regulação desse direito para proteção da infância e da adolescência. Em consonância com os demais direitos humanos e com o fim precípuo das normas internacionais de direitos humanos, a proteção da dignidade humana, a Convenção proíbe a propaganda a favor da guerra e a incitação ao ódio, à discriminação, ao crime ou à violência.

Outro documento relevante sobre a liberdade de expressão, no âmbito do Sistema Interamericano de Direitos Humanos (SIDH) é a Declaração de Chapultepec. A Declaração,

\footnotetext{
${ }^{6}$ Atualmente, a OEA congrega os 35 Estados independentes das Américas e constitui o principal fórum governamental político, jurídico e social do Hemisfério. Para atingir os seus objetivos mais importantes, a OEA baseia-se em seus principais pilares que são a democracia, os direitos humanos, a segurança e o desenvolvimento. São membros originais, que se reuniram em Bogotá, em 1948, para a assinatura da Carta da OEA: Argentina, Bolívia, Brasil, Chile, Colômbia, Costa Rica, Cuba, Equador, El Salvador, Estados Unidos da América, Guatemala, Haiti, Honduras, México, Nicarágua, Panamá, Paraguai, Peru, República Dominicana, Uruguai e Venezuela (República Bolivariana da). Posteriormente, tornaram-se membros: Barbados, Trinidad e Tobago (1967), Grenada (1975), Suriname (1977), Dominica (Commonwealth da), Santa Lúcia (1979), Antígua e Barbuda, São Vicente e Granadinas (1981), Bahamas (Commonwealth da) (1982), St. Kitts e Nevis (1984), Canadá (1990), Belize, Guiana (1991).

$\mathrm{O}$ caso de Cuba tem algumas peculiaridades. A participação do Estado no sistema interamericano foi excluída em 1962 e, em 03 de junho de 2009, os Ministros de Relações Exteriores das Américas declararam que a participação da República de Cuba na OEA será o resultado de um processo de diálogo iniciado na solicitação do Governo de Cuba, e de acordo com as práticas, propósitos e princípios da OEA.
} 
redigida por 100 especialistas a pedido da Sociedade Interamericana de Imprensa (SIP), diz da liberdade de expressão e de imprensa e foi adotada pela Conferência Hemisférica sobre Liberdade de Expressão realizada em Chapultepec, México, no dia 11 de março de 1994. Na declaração, a liberdade de expressão é tratada em suas três dimensões (informar, informar-se e ser informado) e vista como um direito inalienável do povo, jamais uma concessão dos governos. Entre os princípios, o documento dispõe sobre o dever de as autoridades dispor ao cidadão informações sobre o setor público, critica a censura prévia e a violência contra jornalistas.

Atualmente, segundo dados da Sociedade Interamericana de Imprensa (2016), 30 Estados Americanos já assinaram o documento desde 1994, tendo o compromisso sido reafirmado por diversos chefes de Estado destes países ao longo dos seus 22 anos ${ }^{7}$. Embora a Declaração não possua valor jurídico, o fato de os Estados a terem assinado sinaliza um compromisso institucional do governo em atuar na proteção e efetividade do direito à liberdade de expressão. Os dez princípios da Declaração de Chapultepec serviram de base para a Declaração de Princípios sobre a Liberdade de Expressão, um dos pilares para a atuação da Comissão Interamericana.

A Declaração de Princípios sobre a Liberdade de Expressão foi aprovada pela CIDH em 19 de outubro de $2000^{8}$ e elenca 13 princípios de proteção à liberdade de expressão. A Declaração é considerada o mais completo documento oficial sobre liberdade de expressão no sistema interamericano até o momento (MENDEL, 2009) e reafirma o conteúdo desse direito humano contido em outros documentos. A liberdade de expressão é vista como um requisito indispensável para a própria existência de uma sociedade democrática, exercendo-a em suas três variáveis: buscar, receber e divulgar informação e opiniões livremente.

Todos esses documentos integram o Direito Internacional dos Direitos Humanos e, no âmbito dos Estados americanos, o Chile aderiu a todos. No próximo tópico analisaremos a incorporação desse sistema normativo na ordem interna chilena.

\footnotetext{
${ }^{7}$ De acordo com a Sociedade Interamericana de Imprensa, os Estados que assinaram o documento até o momento foram: México, Guatemala, Panamá, Argentina, Paraguai, Bolívia, El Salvador, Nicarágua, Honduras, Colômbia, Estados Unidos da América (1994), Costa Rica, Brasil (1996), Chile (1997), Jamaica, Gramada, Belice (1998), Equador (1999), República Dominicana (2000), Peru (2001), Bahamas, San Vicente y las Granadinas, Dominica, Suriname, San Cristóbal y nevis, Guiana, Antillas Holandesas, Aruba, Trinidad e Tobago, Antigua e Barbuda (2002).

${ }^{8} 108^{\text {a }}$ Sessão Regular, 19 de outubro de 2000.
} 


\section{A CONSTITUIÇÃO CHILENA E A PROTEÇÃO AOS DIREITOS HUMANOS}

No entendimento jurisprudencial, desde 1952 estava pacificado o posicionamento interpretativo da supralegalidade de tratados internacionais ante o ordenamento jurídico chileno. Contudo, no âmbito da Constituição Política da República do Chile de 1980 não existia um dispositivo que estabelecesse qual a hierarquia dos tratados internacionais gerais e de direitos humanos, em especial, nem o procedimento para a sua incorporação. $\mathrm{O}$ artigo 50 previa apenas que "La aprobación de un tratado se someterá a los trámites de uma ley." (CHILE, 1980). Diante dessa lacuna, a questão se resolvia pela via da interpretação judicial.

Viñas (2008) explica que existem quatro fases do tratamento jurisprudencial acerca da hierarquia dos tratados de direitos humanos no Chile. Na primeira etapa interpretativa, que prevaleceu desde a Constituição de 1980 até a reforma 1989, os tribunais atribuíam a tratados internacionais o mesmo status normativo referente à lei. Aqui, os pactos promulgados mas que porventura não eram publicados por falta de ação do executivo, não possuíam vigência interna e, portanto, suas obrigações não eram consideradas vinculantes para o Estado chileno. $\mathrm{O}$ encerramento desse ciclo ocorreu com o acréscimo do inciso II ao artigo $5^{\circ}$ pela reforma constitucional $^{9}$ de 1989 (Lei ${ }^{\circ} 18.825$, de 17 de agosto de 1989), que determinou o dever estatal de respeito aos tratados internacionais vigentes ${ }^{10}$. A partir daí, vigorosas divergências de opinião sobre a interpretação da hierarquia dos direitos humanos foram suscitadas (ROJAS, 2012), o que inaugurou o segundo ciclo interpretativo.

Com a entrada em vigor da referida emenda constitucional, a discussão se circunscreveu a determinar se ditos direitos têm uma hierarquia legal, supralegal, constitucional ou supraconstitucional, tendo consolidado o entendimento de que a emenda reafirmou o estatuto constitucional dos direito humanos ${ }^{11}$ :

Por tanto, la enmienda al inciso segundo del artículo $5^{\circ}$ reafirmó la categoría constitucional de los derechos humanos consagrados en los tratados internacionales vigentes en Chile y agregó al rango constitucional a los derechos y obligaciones establecidos en los tratados internacionales ratificados por Chile en todo su acervo: catálogo de derechos con su acervo jurisprudencial, obligaciones generales, normas de resolución de conflictos (suspensión de derechos y restricciones legítimas), de

\footnotetext{
${ }^{9}$ No sistema constitucional chileno o processo de reforma ocorre através de lei com procedimento e quorum diferenciado em relação às demais leis do processo legislativo: La única diferencia procedimental entre la reforma constitucional y el procedimiento legislativo radica en la facultad que ostenta el Presidente de la República para recurrir al plebiscito, en caso de que sea necesario dirimir desacuerdos entre el Jefe del Estado y el Parlamento, cuando el legislativo no apoye un veto presidencial. Si atendemos al quórum, la diferencia se difumina igualmente. Así, la diferencia de quórum entre la regla general de la reforma constitucional y la requerida para la aprobación de una Ley Orgánica constitucional es menor que la establecida en el plano de la legalidad entre la Ley Orgánica constitucional y la Ley de quórum cualificado. (SIERRA; FERRER, 2005, p. 5). ${ }^{10}$ "Es deber de los órganos del Estado respetar y promover tales derechos, garantizados por esta Constitución, así como por los tratados internacionales ratificados por Chile y que se encuentren vigentes" (CHILE, 1989).

${ }^{11}$ Importante ressaltar que a tese da supraconstitucionalidade é uma possibilidade legítima, como acentua Rojas (2012, p. 23) pois "los derechos humanos entendidos por la propia Constitución como un límite a la soberanía del Estado podrían ser considerados jerárquicamente superiores a la misma Constitución.”.
} 
forma tal que se haga efectivo el pleno goce y ejercicio de los mismos. (ROJAS, 2012, p. 23)

Comentando o referido artigo da Constituição Chilena, Vieira-Gallo e Lubbert (2012) o consideram marco para que o Tribunal Constitucional chileno atuasse na redemocracia do país em função do novo tratamento dado aos tratados de direitos humanos "en consonancia con la transformación del sistema internacional” (VIEIRA-GALLO; LUBBERT, 2012, p. 114). Tais debates, que perduraram durante todo o segundo ciclo, findaram com a declaração por parte do Tribunal Constitucional chileno do status de supralegalidade dos tratados internacionais em 1994, a partir do julgamento de dois casos (Lumi VidelayUribe e TambleyVan Jurick). Nesse período, as discussões judiciais, extremamente divergentes, giraram em torno da prisão civil por dívida e da lei de anistia.

A terceira fase esteve compreendida entre 1994 e 2005, ano em que a Corte IDH, no julgamento do caso Almonacid Arellano vs. Chile, determinou à justiça chilena que exercesse o controle de convencionalidade em relação à sua Constituição ${ }^{12}$. Nessa fase, a partir de 1998 , com o julgamento do Caso Poblete Córdova, relacionado à lei de anistia chilena, os tratados de direitos humanos passaram a ser considerados hierarquicamente superiores às leis comuns, mas inferiores às leis de ordem pública (VIÑAS, 2008).

A quarta fase, que ainda se desenrola, foi iniciada com a reforma constitucional promovida em 2005 (Lei 20.050, de 26 de agosto de 2005), responsável pela modificação do artigo 54 da Constituição ao dispor como atribuição do Congresso “aprobar o desechar los tratados internacionales que le presentare el Presidente de la Republica antes de su ratificación" (CHILE, 2005), tornando inequívoca a prevalência dos tratados sobre as leis internas, somente modificados "en la forma prevista en los propios tratados o de acuerdo a las normas generales de Derecho Internacional.” (CHILE, 2005).

Em relação à hierarquia dos tratados internacionais de direitos humanos no Chile, Rojas (2012) afirma que a discussão, acentuada com a reforma constitucional de 1989, ao acrescer a parte final do inciso segundo do art. 5 da Constituição Chilena de 1980 para dispor que "Es deber de los órganos del Estado respetar y promover tales derechos, garantizados por

\footnotetext{
${ }^{12}$ A CIDH submeteu o caso em 11 de julho de 2005, os fatos expostos na demanda se referiam à suposta falta de investigação e punição dos responsáveis pela execução extrajudicial do senhor Almonacid Arellano, a partir da aplicação do Decreto no 2.191, lei de anistia adotada no Chile em 1978, assim como à suposta falta de reparação adequada em favor de seus familiares. Neste julgamento, a Corte estabeleceu que "o Poder Judiciário deve exercer uma espécie de 'controle de convencionalidade' entre as normas jurídicas internas aplicadas a casos concretos e a Convenção Americana sobre Direitos Humanos” (CIDH, 2006). Desde então, a CIDH tem entendido que o controle de convencionalidade por parte dos juízes e tribunais locais é um dever que decorre da ordem pública internacional, não podendo ser afastado por qualquer pretexto, sob pena de responsabilidade internacional do Estado (MAZZUOLI, 2015).
} 
esta Constitución, así como por los tratados internacionales ratificados por Chile y que se encuentren vigentes." (CHILE, 1989).

\section{CASOS EMBLEMÁticos DO CHILE NA CORTE INTERAMERICANA DE DIREITOS HUMANOS}

O Chile faz parte do Sistema Internacional dos Direitos Humanos tanto em nível universal (Sistema das Nações Unidas), quanto regional (SIDH) e ratificou numerosos instrumentos desses sistemas. Essa circunstância possibilita o uso da jurisdição internacional. Assim, a violação de direitos humanos por parte do Chile faz surgir a possibilidade de responsabilização internacional do Estado. No âmbito regional, tais violações são competência da CIDH que, entendendo ser o caso, pode provocar a Corte IDH. Neste tópico, analisaremos casos considerados emblemáticos sobre a temática da liberdade de expressão contra o Chile processados ante a Corte IDH para, em seguida, estudarmos as mudanças promovidas no direito doméstico chileno em resposta aos mandamentos da Corte IDH.

\subsection{Caso "A Última Tentação de Cristo" (Olmedo Bustos e outros vs. Chile)}

Em 15 de janeiro de 1999, a CIDH submeteu perante a Corte IDH demanda contra o Chile, oriunda de denúncia apresentada pela Associação de Advogados pelas Liberdades Públicas A.G., em representação dos senhores Juan Pablo Olmedo Bastos, Ciro Colombara López, Claudio Márquez Vidal, Alex Muñoz Wilson, Matías Insunza Tagle e Hernán Aguirre Fuentes e "do restante dos habitantes da República do Chile", para que a Corte decidisse se houve violação aos artigos 13 (liberdade de pensamento e de expressão) e 12 (liberdade de consciência e de religião) da Convenção Americana de Direitos Humanos diante da proibição de exibição do filme "A última tentação de Cristo" ${ }^{13}$.

No momento em que aconteceu a proibição, a Constituição do Chile em seu artigo 19, n. 12, confiava à lei o estabelecimento de um sistema de censura para a exibição e publicidade da produção cinematográfica. O Decreto-lei nº 679/1974 conferiu tal atribuição ao Conselho de Classificação Cinematográfica, órgão ligado ao Ministério da Educação. Em 29 de novembro de 1988, o Conselho proibiu a exibição do filme, mas em 11 de novembro de 1996

\footnotetext{
13 "A última tentação de Cristo" é um filme norte-americano, de 1988, dirigido por Martin Scorcese. O filme retrata a vida de Jesus Cristo e a sua luta contra várias formas de tentação, incluindo medo, dúvida, depressão, relutância e luxúria. $\mathrm{O}$ filme inclui um aviso explicando que se afasta da interpretação bíblica comumente aceita da vida de Jesus, e não se baseia nos Evangelhos.
} 
autorizou a exibição para espectadores maiores de 18 anos. No entanto, Sergio García Valdés, Vicente Torres Irarrázabel e outros cidadãos chilenos ingressaram com recurso perante a Corte de Apelações de Santiago, alegando a violação à honra de Jesus Cristo, da Igreja Católica e de si mesmos, tendo a Corte tornado sem efeito a resolução administrativa do Conselho. A decisão foi confirmada pela Corte Suprema de Justiça em 17 de junho de 1997.

A CIDH requereu que a Corte IDH ordenasse ao Chile que permitisse a exibição do filme; adequasse as suas normas constitucionais e legais ao direito à liberdade de expressão nos termos da Convenção Americana a fim de eliminar a censura prévia; assegurasse que os órgãos do poder público, no exercício de suas funções, tornassem efetivos os direitos à liberdade de expressão, consciência e religião, reconhecidos na Convenção; e, reparasse as vítimas do caso pelo dano sofrido, bem como o reembolsasse dos custos do litígio.

A Corte IDH, na sentença de 05 de fevereiro de 2001, determinou que o Chile, em respeito ao artigo 13 da Convenção, deveria modificar seu ordenamento jurídico com o objetivo de suprimir a censura prévia, para permitir a exibição do filme "A última tentação de Cristo" e que o Estado está obrigado a respeitar o direito à liberdade de expressão e garantir seu livre e pleno exercício a todas as pessoas sujeitas à sua jurisdição. Em relação à reparação, a Corte entendeu que a sentença, por si só, já seria forma de reparação e satisfação moral para as vítimas, mas houve a condenação do Estado ao reembolso dos custos do litígio.

\subsection{Caso Palamara Iribarne vs. Chile}

A CIDH apresentou demanda perante a Corte IDH em 13 de abril de 2004, após denúncia com o objetivo de declarar que o Estado do Chile era responsável pela violação dos direitos previstos nos artigos 13 (liberdade de pensamento e expressão) e 21 (direito à propriedade privada), em relação às obrigações estabelecidas nos artigos 1.1 (obrigação de respeitar os direitos) e $2^{\circ}$ (dever de adotar disposições de direito interno) da Convenção Americana diante da violação desses direitos em face do cidadão chileno Humberto Antonio Palamara Iribarne.

O Sr. Palamara Iribarne, engenheiro naval mecânico, atuou nas forças armadas do Chile de 1972 a 01 de janeiro de 1993, como Oficial do Departamento de Operações Navais da III Zona Naval. Em 15 de fevereiro de 1993, Palamara comentou com o comandante-chefe da III Zona Naval, Hugo Bruna Greene, que havia escrito livro intitulado "Ética e Serviços de Inteligência”. O comandante proibiu a publicação do livro sem prévia autorização. Em 18 de fevereiro, Palamara solicitou, por escrito, a publicação ao comandante, que remeteu o pedido 
ao general chefe do estado maior. Em 01 de março de 1993, Palamara foi notificado de que a publicação não havia sido autorizada sob o fundamento de vulneração à segurança e à defesa nacional. Entretanto, Palamara informou estar disposto a publicar sem autorização.

Diante da negativa em interromper a publicação do livro, Palamara foi processado penalmente pelos delitos de desobediência e de descumprimento dos deveres militares. Em diferentes datas do mês de março daquele ano foram apreendidas 900 cópias do livro em sua residência, o disquete com o texto integral do livro e o teve apagado do computador. Palamara foi preso e libertado sob fiança. A esposa e filha de Palamara interpuseram recurso perante a Corte de Apelações questionando a legalidade do processo penal militar, principalmente em relação ao devido processo legal. A Corte de Apelações, um dos órgãos da jurisdição chilena responsável pelos julgamentos de recursos, se manifestou no sentido de não interferência em atos de outros juízes de distinta jurisdição, a concessão de entrevistas à imprensa para comentar os fatos que levou à imputação de novos fatos pelo delito de desobediência e desacato. O resultado final perante a justiça chilena foi a sua condenação criminal definitiva, a suspensão de seu cargo público, o confisco dos 900 exemplares do livro e o pagamento das custas do processo.

Na demanda apresentada à Corte IDH, a CIDH sustentou que a proibição de censura prévia envolve a proibição de qualquer ato que impeça a distribuição de um livro materialmente existente e que o tipo penal de desacato, previsto no Código Penal Chileno, é incompatível com o artigo 13 da Convenção Americana. Assim, a condenação de Palamara por este delito, fundada em suas críticas ao comportamento de funcionários públicos, constitui a responsabilização ao exercício da liberdade de expressão que não é necessária em uma sociedade democrática.

A sentença de 22 de novembro de 2005 reconheceu a violação do artigo 13 em relação às obrigações estabelecidas nos artigos 1.1 e 2, artigos 21.1 e 21.2, em relação ao artigo 1.1, e os artigos 7, 8 e 25, em relação aos artigos 1.1 e 2. O Chile foi condenado a reparar materialmente as vítimas, a indenizar pelo dano imaterial causado, a permitir a publicação do livro, devolver os exemplares confiscados, a publicação em diário oficial da sentença condenatória, e adotar, em um prazo razoável, todas as medidas necessárias para modificar qualquer norma interna que seja incompatível com os princípios internacionais em matéria de liberdade de pensamento e expressão. Ademais, o Chile deverá estabelecer, por meio de sua legislação, os limites de competência dos tribunais militares, de forma que nenhum civil seja submetido à jurisdição dos tribunais militares, além de os seus membros revestirem-se das garantias de competência, imparcialidade e independência, próprias do Poder Judiciário. 


\subsection{Caso Claude Reyes e outros vs. Chile}

Em 08 de julho de 2005, a CIDH apresentou demanda, originada da denúncia feita por um grupo integrado pela "Clínica Jurídica de Interés Público" da Universidade Diego Portales, as organizações chilenas "ONG Forja", "Fundación Terram" e "Corporación la Morada", as organizações argentinas "Instituto de Defensa Legal Del Perú", a "Fundación Poder Ciudadano" e a "Asociacón para los Derechos Civiles" e os senhores Baldo Prokurica, Oswaldo Palma Flores, Guido Girardo Lavin e Leopoldo Sánches Grunert, com o fim de ver declarada a responsabilidade do Chile pela violação dos direitos consagrados nos artigos 13 (Liberdade de Pensamento e de Expressão) e 25 (Direito à Proteção Judicial) da Convenção Americana, em relação às obrigações estabelecidas nos artigos 1.1 (Obrigação de Respeitar os Direitos) e $2^{\circ}$ (Dever de Adotar Disposições de Direitos Interno), em face dos senhores Marcel Claude Reyes, Sebastián Cox Urrejola e Arturo Longton Guerrero.

Os fatos expostos na demanda pela Comissão teriam ocorrido entre maio e agosto de 1998 e referem-se à suposta negativa do Estado em oferecer aos senhores Marcel Claude Reyes, Sebastián Cox Urrejola e Arturo Longton Guerrero toda a informação que requeriam do Comitê de Investimentos Estrangeiros em relação à empresa florestal Trillium e ao Projeto Rio Condor, projeto este que determinava o desflorestamento a ser realizado na décima segunda região do Chile. O conjunto de intervenções na natureza que os peticionários ponderavam estar previstas no projeto era considerado prejudicial ao meio ambiente, bem como fator a impedir o desenvolvimento sustentável do Chile. O Estado chileno se recusou a prestar a informação sob o argumento de que o tipo de solicitação violaria o direito de confidencialidade das empresas envolvidas.

A CIDH afirmou que tal negativa foi dada sem que o Estado argumentasse justificação válida de acordo com a legislação chilena, bem como porque, supostamente, não lhes concedeu um recurso judicial efetivo para impugnar uma violação do direito ao acesso à informação e não lhes assegurou os direitos ao acesso à informação e à proteção judicial, nem contou com mecanismos estabelecidos para garantir o direito ao acesso à informação pública. A CIDH também solicitou à Corte IDH que, de acordo com o artigo 63.1 da Convenção Americana, ordenasse ao Estado que adotasse determinadas medidas de reparação e ordenasse o pagamento das custas e gastos gerados na tramitação do caso na jurisdição interna e perante os órgãos do Sistema Interamericano. 
Na sentença de 19 de setembro de 2006, a Corte IDH afirmou que a sua jurisprudência contempla vasto conteúdo relacionado ao direito à liberdade de pensamento e de expressão, por meio da descrição de suas dimensões individual e social, das quais se desenvolvem série de direitos que se encontram protegidos pelo art. 13 da Convenção Americana. Assim, a atuação da Corte IDH protege o direito de toda pessoa solicitar o acesso à informação sob o controle do Estado, com as exceções permitidas sob o regime das restrições, o que enfatiza a importância que os membros da OEA dão ao assunto, conforme documentos internacionais por eles adotados.

A Corte IDH condenou o Chile a prestar a informação solicitada pelas vítimas ou adotar decisão fundamentada sobre sua negação e fixou a obrigação de o Estado adotar as medidas legislativas ou de outro caráter necessárias para tornarem efetivos tais direitos e liberdades. Determinou, portanto, que fosse assegurado procedimento administrativo eficaz, sob a responsabilidade de profissionais capacitados e com o estabelecimento de prazos razoáveis para a tomada de decisões. De outro lado, a Corte IDH ressaltou os importantes avanços normativos no âmbito interno chileno que ocorriam naquele momento, como a tramitação da lei de acesso à informação pública e como o recurso judicial especial para amparar o acesso à informação.

\section{AS CONDENAÇÕES DO ESTAdo CHILENO PERANTE A CORTE INTERAMERICANA E AS MUDANÇAS CONSTITUCIONAIS: CONCRETIZAÇÃO DO DIREITO HUMANO À LIBERDADE DE EXPRESSÃO}

De acordo com o Pacto de San José, as sentenças da Corte IDH são definitivas e inapeláveis (artigo 67), ou seja, são obrigatórias para os Estados que reconheceram a sua competência em matéria contenciosa. As sentenças da Corte IDH têm caráter vinculante, e a determinação de seu cumprimento está prevista no art. $68, \S \S 1^{\circ}$ e $2^{\circ}$ da Convenção americana. Além disso, o desenvolvimento da prática e da jurisprudência no âmbito regional, no entender de Mazzuoli (2015, p. 972) "parecem exigir que suas decisões sejam de cumprimento direto no âmbito nacional (autoexecutivas, autoexecutáveis ou self executing), ainda que a determinação de tal caráter dependa geralmente de decisões constitucionais do Estado".

Ademais, além de os Estados membros terem a obrigação de adequar sua legislação interna a tratados e a outros instrumentos de proteção de direitos humanos, é dever daqueles não editar leis ou adotar práticas que os violem. Esse foi o entendimento da Corte IDH ao responder questão apresentada pela $\mathrm{CIDH}$ acerca dos efeitos jurídicos, relativamente às 
obrigações internacionais, de lei que violasse manifestamente as obrigações contraídas por um Estado ao ratificar a Convenção Americana. Na Opinião Consultiva n ${ }^{\circ}$ 14, de 09 de dezembro de 1994, a Corte IDH afirmou que se constitui em violação capaz de gerar, quando afeta direitos e liberdades protegidos de determinados indivíduos, responsabilidade internacional.

No entanto, o cotidiano vivenciado nos Estados submetidos à jurisdição da Corte IDH revela a existência de violação aos direitos humanos, seja desrespeitando direitos também previstos em suas Constituições, seja aplicando a legislação interna lato sensu menos favorável ao ser humano. Nos casos analisados neste artigo, durante o cumprimento dos mandamentos da Corte IDH, o Chile realizou mudanças no seu ordenamento jurídico com vistas a atender o dever de concretizar o direito humano à liberdade de expressão.

Em cumprimento ao mandamento da Corte IDH no caso "A Última Tentação de Cristo" (Olmedo Bustos e outros vs. Chile), o Chile modificou o texto da sua Constituição com o objetivo de suprimir a censura prévia. Com a Lei no 19.742, publicada em 25 de agosto de 2001, a Constituição Chilena, em seu artigo 19, n 12, passou a vedar expressamente a prévia censura e criou um sistema de classificação. Esse caso demonstra como a atuação jurisdicional da Corte IDH pode influenciar os Estados, pois, apesar de na época da sentença já existir um projeto de reforma constitucional sobre este tema, datado de 14 de abril de 1997, a mudança constitucional somente ocorreu após a Corte IDH ter se pronunciado pela necessidade de mudança constitucional.

Todavia, o mesmo não pode ser verificado no caso Palamara Iribarne vs. Chile. O cumprimento do mandamento de mudança do ordenamento jurídico doméstico em relação à derrogação e modificação de qualquer norma interna que seja incompatível com as diretivas internacionais em matéria de liberdade de expressão e pensamento, bem como sobre a jurisdição militar (para que a jurisdição penal limite-se somente ao conhecimento de delitos de função cometidos por militares em serviço ativo de acordo com o devido processo legal) não foram cumpridas até o momento, conforme o último relatório de supervisão emitido pela Corte IDH em 11 de julho de 2011. A resistência para o cumprimento da sentença da Corte IDH contribui tanto para a ineficácia da decisão quanto expõe as deficiências do sistema em relação à execução das sentenças da Corte IDH, especialmente em relação a temas limítrofes.

Em Claude Reyes e outros vs. Chile, o último relatório de acompanhamento, de 24 de novembro de 2008, arquivou o caso por cumprimento integral da sentença. Em relação às medidas de concretização do acesso às informações sob controle do Estado, o Chile publicou em 20 de agosto de 2008 a "Ley de Transparencia de la Función Pública y Acceso a la 
Información de la Administración del Estado", que estabelece princípios, direitos e procedimento para o acesso à informação.

\section{CONCLUSÃO}

Ao retomarmos o projetado para este artigo, conforme proposto na introdução, e o caminho percorrido pela pesquisa nos itens anteriores, deparamo-nos com uma ainda inicial resposta para o problema a que procuramos responder e que possui vieses metodológicos e valorativos. A expansão do direito humano à liberdade de expressão, em suas três vertentes, ao longo da codificação dos direitos humanos na ordem internacional, evidencia direito que se constrói no cotidiano do espaço público, em que política e direito se encontram e interconectam. A fim de a liberdade de expressão desenvolver-se tanto como método de superação dos desafios paradoxais do Estado Democrático de Direito quanto como direito individual e coletivo no âmbito da sociedade, é necessário que ela viva no espaço da liberdade e da pluralidade, características próprias da condição humana, como defende por Hannah Arendt. É nas tensões da sociedade democrática que as possibilidades da condição humana se concretizam e nas dimensões próprias do direito de informar, de informar-se e de ser informado encontra-se ínsita a condição de crescimento do ser humano, pois é no livre debate e acesso de ideias que o sujeito se constrói.

O estudo dos casos da Corte IDH escolhidos a partir do recorte proposto, determinado pelos critérios da liberdade de expressão como temática e de o Chile como Estado-parte, demonstra como os fundamentos das decisões que orientam a concepção de liberdade de expressão perante o tribunal na Corte IDH foram sendo aplicados. Em um período compreendido em pouco mais de cinco anos entre a primeira sentença ("A última tentação de Cristo", sentença de 05 de fevereiro de 2001) e a última (Claude Reyes e outros vs. Chile, sentença de 19 de setembro de 2006), as análises jurídicas se tornaram mais complexas e abrangentes.

Nos três casos analisados, a Corte IDH conferiu amplitude ao direito da liberdade de expressão e entendeu seu exercício como fundamental ao ambiente democrático. Esse entendimento jurisprudencial sobre o que representa a liberdade de expressão ante ao paradoxo no qual se sustenta o Estado Democrático de Direito reforça as normas contidas no sistema interamericano que vedam a censura prévia, com as exceções previstas na própria legislação internacional. Salientamos que, nos termos Convenção Americana, estas exceções dizem respeito à proteção à infância e à adolescência, o respeito aos direitos das demais 
pessoas e a proteção da segurança nacional, da ordem pública, ou da saúde ou da moral públicas.

Nas decisões da Corte IDH é ressaltado o baseamento democrático do direito à liberdade de expressão. O primeiro julgamento, “A última tentação de Cristo", é responsável pelo estabelecimento de importantes pontos na jurisprudência do tribunal sobre a matéria, os quais alicerçaram futuras interpretações, sobre as dimensões individual e social desse direito.

Pudemos constatar, também, por intermédio do estudo sistematizado dos casos, que as três demandas apresentam a liberdade de expressão em suas três vertentes (informar, informar-se e ser informado). Em "A última tentação de Cristo" prevalece o direito a receber informações; no caso Palamara Iribarne vs. Chile, o direito de difundi-las; e em Claude Reyes e outros vs. Chile está o direito de buscar informações, o qual se refere à dimensão da liberdade de expressão em papel de controle democrático, a partir do acesso do cidadão às informações do poder público.

O estudo desses casos também conduz à reflexão do tema do cumprimento das sentenças internacionais. Nas demandas analisadas, apesar dos problemas geralmente apontados sobre a falta de força coativa das decisões da Corte IDH e dos Tribunais Internacionais em geral, além de o próprio SIDH ainda não dispor de um sistema eficaz de execução das sentenças da Corte na ordem interna dos Estados, houve o cumprimento da maior parte de seus mandamentos. Todavia, em um tema limítrofe como a jurisdição militar, a Corte encontrou resistência para a sua efetivação. Verifica-se, pois, a necessidade de o sistema interamericano de direitos humanos fortalecer-se no âmbito da atuação jurisdicional da Corte IDH, a fim de essa atuação constituir-se em maior grau de legitimidade para a efetivação dos direitos humanos no continente.

\section{REFERÊNCIAS}

ÁVILA, Flávia de. Direito e Direitos Humanos: abordagem histórico-filosófica e conceitual. Curitiba: Appris, 2014.

ARENDT, Hannah. A Condição Humana. 10 ed. Rio de Janeiro: Forense, 2007.

CANOtIlHO, J. J. Gomes. Direito Constitucional e Teoria da Constituição. Coimbra: Almedina, 2003.

COMITÉ DE DERECHOS HUMANOS. Observación general no 34 - Artículo 19 Libertad de opinión y libertad de expressión. Disponível em: <http://conf- 
dts1.unog.ch/1\%20SPA/Tradutek/Derechos_hum_Base/CCPR/00_2_obs_grales_Cte\%20Der Hum\%20\%5BCCPR\%5D.html>. Acesso em: 02 abr. 2016.

COMISSÃO INTERAMERICANA DE DIREITOS HUMANOS (CIDH). Declaração de Princípios sobre Liberdade de Expressão. Disponível em:

<http://www.cidh.oas.org/basicos/portugues/s.convencao.libertade.de.expressao.htm>. Acesso em: 01 abr. 2016.

CORTE INTERAMERICANA DE DIREITOS HUMANOS. Caso "La ultima tentación de cristo" (Olmedo Bustos y otros). Disponível em: <

http://www.corteidh.or.cr/docs/supervisiones/tentacion_28_11_03.pdf>. Acesso em: 02 abr. 2016.

CORTE INTERAMERICANA DE DIREITOS HUMANOS. Caso Palamara Iribarne vs. Chile. Disponível em:

<http://www.corteidh.or.cr/docs/supervisiones/palamara_01_07_11.pdf>. Acesso em: 02 abr. 2016.

CORTE INTERAMERICANA DE DIREITOS HUMANOS. Caso Claude Reyes y otros vs. Chile. Disponível em: < http://www.corteidh.or.cr/docs/supervisiones/reyes_24_11_08.pdf>. Acesso em: 02 abr. 2016.

CHILE. Historia de la Ley $\mathbf{n}^{\mathbf{0}}$ 19.742. Reforma constitucional que elimina la censura cinematográfica sustituyéndola por un sistema de calificación y que consagra el derecho a la libre creación artística. Disponível em: <www.leychile.cl/>. Acesso em: 01 abr. 2016.

CHILE. Ley 20050, de 26 ago 2005. Reforma Constitucional. Disponível em:

<http://www.leychile.cl/Navegar?idNorma=241331\&idVersion=2005-08-26>. Acesso em: 30 mar. 2016.

MAZZUOLI, Valério de Oliveira. Curso de Direito Internacional Público. $9^{a}$ ed. São Paulo: Editora Revista dos Tribunais, 2015.

MENDEL, Toby. Liberdade de informação: um estudo de direito comparado. $2^{\mathrm{a}} \mathrm{Ed}$. Brasília: UNESCO, 2009.

MENDES, Gilmar. A jurisdição constitucional no Brasil e seu significado para a liberdade e a igualdade. Disponível em: <

http://www.stf.jus.br/arquivo/cms/noticiaArtigoDiscurso/anexo/munster_port.pdf >. Acesso em: 20 jan. 2016.

MENDES, Gilmar. Curso de Direito Constitucional. $10^{\text {a }}$ Ed. rev. e atual. São Paulo: Saraiva, 2015.

NAÇÕES UNIDAS. Assembleia Geral. Declaração universal dos direitos humanos. Adotada e proclamada pela resolução 217 A (III) da Assembléia Geral das Nações Unidas em 10 de dezembro de 1948. Nova Iorque, 1948. Disponível em:

< http://unesdoc.unesco.org/images/0013/001394/139423por.pdf >. Acesso em: 10 mar. 2016. 
NAÇÕES UNIDAS. Pacto Internacional sobre Direitos Civis e Políticos. Disponível em: <http://www.planalto.gov.br/ccivil_03/decreto/1990-1994/d0592.htm>. Acesso em: 10 mar. 2016.

ORGANIZAÇÃO DOS ESTADOS AMERICANOS. Estados Membros. Disponível em: < http://www.oas.org/pt/sobre/estados_membros.asp>. Acesso em: 01 abr. 2016.

ORGANIZAÇÃO DOS ESTADOS AMERICANOS. Decisões da Corte IDH. Disponível em: <http://www.oas.org/pt/cidh/expressao/jurisprudencia/si_decisiones_corte.asp >. Acesso em: 10 mar. 2016.

ROJAS, Claudio Nash. Derecho Internacional de Los Derechos Humanos en Chile Recepción y aplicación en el ámbito interno. Universidad de Chile: Santiago de Chile, 2012.

SIERRA, José Manuel; FERRER, Covadonga. La Reforma Constitucional en Chile. Disponível em: <http://www2.uned.es/dpto-derechopolitico/Comunicacion_Martinez_Ferrer.pdf>. Acesso em: 03 abr. 2016.

SISSE, Lamine. Liberdade de Expressão e Democracia na Guiné Bissau. 222 f. Tese (doutorado). Universidade Federal da Bahia, Faculdade de Direito, 2015.

TORRES, Ana Paula Repolês. Pensando a liberdade de "expressão" com Hannah Arendt. Prometeus Filosofia em Revista. Disponível em: < http://seer.ufs.br/index.php/prometeus/article/view/792>. Acesso em: 03 abr. 2016.

SOCIEDADE INTERAMERICANA DE IMPRENSA. Declaração de Chapultepec. 1994. Disponível em: <http://www.direitoshumanos.usp.br/index.php/Documentos-n\%C3\%A3oInseridos-nas-Delibera\%C3\%A7\%C3\%B5es-da-ONU/declaracao-de-chapultepec1994.html>. Acesso em: 01 abr. 2016.

SOCIEDADE INTERAMERICANA DE IMPRENSA. Chefes de Estado. Disponível em: <http://pt.sipiapa.org/contenidos/chefes-de-estado.html>. Acesso em: 01 abr. 2016.

VIERA-GALLO, José Antonio; LÜBBERT, Valeria. Los tratados sobre derechos humanos en la jurisprudencia chilena. Disponível em:

<http://www.revistaei.uchile.cl/index.php/REI/article/viewFile/20878/22063>. Acesso em: 20 mar. 2016.

VIÑAS, Miriam Lorena Henríquez. Jerarquía de los tratados de derechos humanos: análisis jurisprudencial desde el método de casos. Disponível em: <http://www.scielo.cl/scielo.php?pid=S0718-52002008000100004\&script=sci_arttext >. Acesso em: 10 mar. 2016. 